\title{
BMJ Open Injuries in mothers hospitalised for domestic violence-related assault: a whole-population linked data study
}

\author{
Vishal Mahesh Bulsara (D) , ${ }^{1,2}$ Max K Bulsara (D) , ${ }^{3}$ Jim Codde, ${ }^{3}$ David Preen, ${ }^{1}$ \\ Linda Slack-Smith (D) , ${ }^{1}$ Melissa O'Donnell ${ }^{1,2}$
}

To cite: Bulsara VM, Bulsara MK, Codde J, et al. Injuries in mothers hospitalised for domestic violence-related assault: a whole-population linked data study. BMJ Open 2021;11:e040600. doi:10.1136/ bmjopen-2020-040600

- Prepublication history for this paper is available online. To view these files, please visit the journal online (http://dx.doi. org/10.1136/bmjopen-2020040600).

Received 19 May 2020 Revised 28 March 2021 Accepted 04 April 2021

Check for updates

C Author(s) (or their employer(s)) 2021. Re-use permitted under CC BY-NC. No commercial re-use. See rights and permissions. Published by BMJ.

${ }^{1}$ School of Population and Global Health, The University of Western Australia, Nedlands, Western Australia, Australia

${ }^{2}$ Telethon Kids Institute,

Nedlands, Western Australia,

Australia

${ }^{3}$ Institute for Health Research, University of Notre Dame Australia School of Medicine, Fremantle, Western Australia, Australia

Correspondence to Dr Vishal Mahesh Bulsara; vishal.bulsara@telethonkids. org.au

\section{ABSTRACT}

Objective To retrospectively assess a cohort of mothers for characteristics of injuries that they have suffered as a result of family and domestic violence (FDV) and which have required admission to a hospital during both the intrapartum and postpartum periods.

Design and setting Retrospective, whole-population linked data study of FDV in Western Australia using the Western Australia birth registry from 1990 to 2009 and Hospital Morbidity Data System records from 1970 to 2013.

Main outcome measures Number of hospitalisations, and mode, location and type of injuries recorded, with particular focus on the head and neck area.

Results There were 11546 hospitalisations for mothers due to FDV. 8193 hospitalisations recorded an injury code to the head and/or neck region. The upper and middle thirds of the face and scalp were areas most likely to receive superficial injuries (58.7\% or 4158 admissions), followed by the mouth and oral cavity $(9.7 \%$ or 687 admissions). Fracture to the mandible accounted for 479 (4.2\%) admissions and was almost equal to the sum of the next three most common facial fractures (nasal, maxillary and orbital floor). Mothers more likely to be hospitalised due to a head injury from FDV included those with more than one child $(\mathrm{OR}=1.17,95 \% \mathrm{Cl} 1.03$ to 1.30$)$ and those with infants ( $<1$ year old) $(\mathrm{OR}=1.40,95 \% \mathrm{Cl} 1.04$ to 1.90$)$ and young children $(<7$ years old) $(0 \mathrm{R}=1.15,95 \% \mathrm{Cl} 1.01$ to 1.30 ).

Conclusions FDV is a serious and ongoing problem and front-line clinicians are in need of evidence-based guidelines to recognise and assist victims of FDV. Mothers with children in their care are a particularly vulnerable group.

\section{INTRODUCTION}

Family and domestic violence (FDV) is a significant problem in our society. The WHO estimates that up to $30 \%$ of women globally experience intimate partner violence in their lifetime. ${ }^{1}$ The Australian Institute of Health and Welfare (AIHW) defines FDV as 'violence between family members, typically where the perpetrator exercises power and control over another person. The most common and pervasive instances occur in intimate (current or former) partner relationships

\section{Strengths and limitations of this study}

This is the first study to examine injuries to mothers due to family and domestic violence (FDV) at a population level.

- It uses over 40 years of population-level data to generate a robust and appropriately statistically powered analysis of injury types and patterns.

- It has broad applications for front-line clinicians and policymakers.

- It is limited by the fact that it only captures FDVrelated assault that has required hospitalisation.

- Much more research is needed in this area to understand how victims of FDV might present with injuries to hospitals.

and are usually referred to as domestic violence'. ${ }^{2}$ The AIHW estimates that during 2014-2015 in Australia almost eight women and two men required admission to hospitals in the country each day after being assaulted by their spouse or partner. ${ }^{2}$ Approximately one woman per week is killed as a result of violence from a current or previous partner. ${ }^{2}$ Alarmingly, Australian Aboriginal and Torres Strait Islander women (hereafter referred to as Aboriginal) are 32 times more likely to be hospitalised due to FDV than non-Aboriginal women. ${ }^{2}$

Published literature examining the types of injuries suffered by victims has indicated that they have tended to occur in the head and neck region and range in spectrum from superficial injuries to fractures and open wounds ${ }^{2}$; however, these data are largely derived from smaller cohorts or encompass shorter periods of observation. ${ }^{3} 4$ At present, clinicians continue to see presentations due to FDV in primary care and emergency settings, despite research and investment in preventive strategies. ${ }^{5}$ There is currently a lack of literature examining both the patterns of injury in FDV and in helping to identify those most at risk of subsequent FDV and re-presentation for 
violence-related injuries. Front-line clinicians are in need of evidence-based guidelines for triaging and managing FDV victims in an emergency or primary care setting as prompt recognition of FDV-related injuries could help to ensure that multidisciplinary teams are engaged early after hospitalisation to assist the victim(s).

In Australia, among women who had experienced violence by a partner, $54 \%$ had children in their care at the time of the violence and $68 \%$ of mothers said their children had seen or heard the violence. ${ }^{6}$ Western Australia's Data Linkage System (WADLS) has enabled the study of large populations, representative of the wider Australian population, ${ }^{7}$ with the identification of familial relationships, making it possible to identify mothers' hospital admissions for assault. This information is essential in providing evidence and informing guidelines for clinicians treating mothers who are victims of FDV. ${ }^{89}$

The purpose of this study was to retrospectively assess a cohort of mothers for characteristics of injuries that they have suffered as a result of FDV and which have required admission to a hospital during both the intrapartum and postpartum periods. The aim of this study was to report the trends in injury and risk factors that may contribute to hospitalisations due to FDV. Due to the number of admissions involving the head and neck region, injuries to this area of the body are explored in more detail.

\section{METHODS}

\section{Study design}

This is a longitudinal cohort study.

\section{Study population: inclusion and exclusion criteria for selecting study subjects}

Records of all women in the Western Australia birth registry who gave birth to a child weighing over $400 \mathrm{~g}$ between 1 January 1990 and 31 December 2009 were extracted, along with hospital admission records that occurred in the state between 1970 and June 2013 routinely recorded in the Hospital Morbidity Data Collection (HMDC). The HMDC is a statutory data collection containing diagnosis (primary and secondary), procedure (principal and secondary) and external cause codes according to the International Statistical Classification of Diseases and Related Health Problems, Ninth Revision (ICD-9; from 1979 to June 1999) and the International Statistical Classification of Diseases and Related Health Problems, Tenth Revision Australian Modification (ICD-10-AM; from July 1999 to April 2019).

\section{Description of procedures}

In order to define a hospital admission as being due to an injury caused by FDV, we searched all hospital records for the birth cohort for ICD codes indicating injury from an intimate partner (external cause code, table 1) which have been validated in previous research using WADLS. ${ }^{10-12}$ Both the external cause and injury codes of interest listed in table 1 had to be present in the data

\begin{tabular}{|c|c|c|}
\hline ICD code & ICD version & Definition \\
\hline \multicolumn{3}{|c|}{ External cause code } \\
\hline E960-E969 & ICD-9 & $\begin{array}{l}\text { Homicide and injury purposely } \\
\text { inflicted by other persons. }\end{array}$ \\
\hline 995.81 & ICD-9 & Adult physical abuse. \\
\hline V71.5 & ICD-9 & $\begin{array}{l}\text { Observation following alleged } \\
\text { rape or seduction. } \\
\text { Examination of victim or } \\
\text { culprit. }\end{array}$ \\
\hline T74.1 & ICD-10-AM & Physical abuse. \\
\hline $\mathrm{T} 74.2$ & ICD-10-AM & Sexual abuse. \\
\hline $\mathrm{T} 74.3$ & ICD-10-AM & Psychological abuse. \\
\hline Z04.4 & ICD-10-AM & $\begin{array}{l}\text { Examination and observation } \\
\text { following alleged rape or } \\
\text { seduction. } \\
\text { Examination of victim or } \\
\text { culprit following alleged rape } \\
\text { or seduction. }\end{array}$ \\
\hline X85-Y09 & ICD-10-AM & Assault. \\
\hline \multicolumn{3}{|l|}{ Injury code } \\
\hline S00-S19 & ICD-10-AM & $\begin{array}{l}\text { Injury to the head and neck } \\
\text { including intracranial injury. }\end{array}$ \\
\hline S20-T32 & ICD-10-AM & $\begin{array}{l}\text { Other injury, poisoning and } \\
\text { certain other consequences of } \\
\text { external causes. }\end{array}$ \\
\hline
\end{tabular}

ICD-9, International Statistical Classification of Diseases and Related Health Problems, Ninth Revision; ICD-10-AM, International Statistical Classification of Diseases and Related Health Problems, Tenth Revision Australian Modification.

for each admission in order to be included in the cohort. Only admissions occurring during pregnancy with or after the birth of the first child were included so as to define 'mothers' for the purposes of this study. Only mothers over the age of 16 years (age of medical consent ${ }^{13}$ ) were included so as to clearly define an 'adult' cohort. Demographic information including age, Aboriginality and a measure of socioeconomic status (SocioEconomic Index For Areas (SEIFA) disadvantage) was obtained from the birth registry data. SEIFA disadvantage assigns one of five levels of disadvantage to census collection districts ( 200 households), ranging from 1 (high disadvantage) to 5 (low disadvantage). ${ }^{14}$ The number of admissions for which an injury code was recorded was then examined according to anatomical regions of the body as defined by injury codes in table 1 drawn from ICD-10. ${ }^{15}$ The head and neck injury cohort was then further defined, prior to analysis, as having one of the head and/or neck injury codes in table 1 (figure 1). ICD-10-AM codes corresponding to specific injuries to specific areas of the head were then isolated and the frequencies were compared to give an assessment of where injuries were occurring most frequently and what injuries were occurring in these 


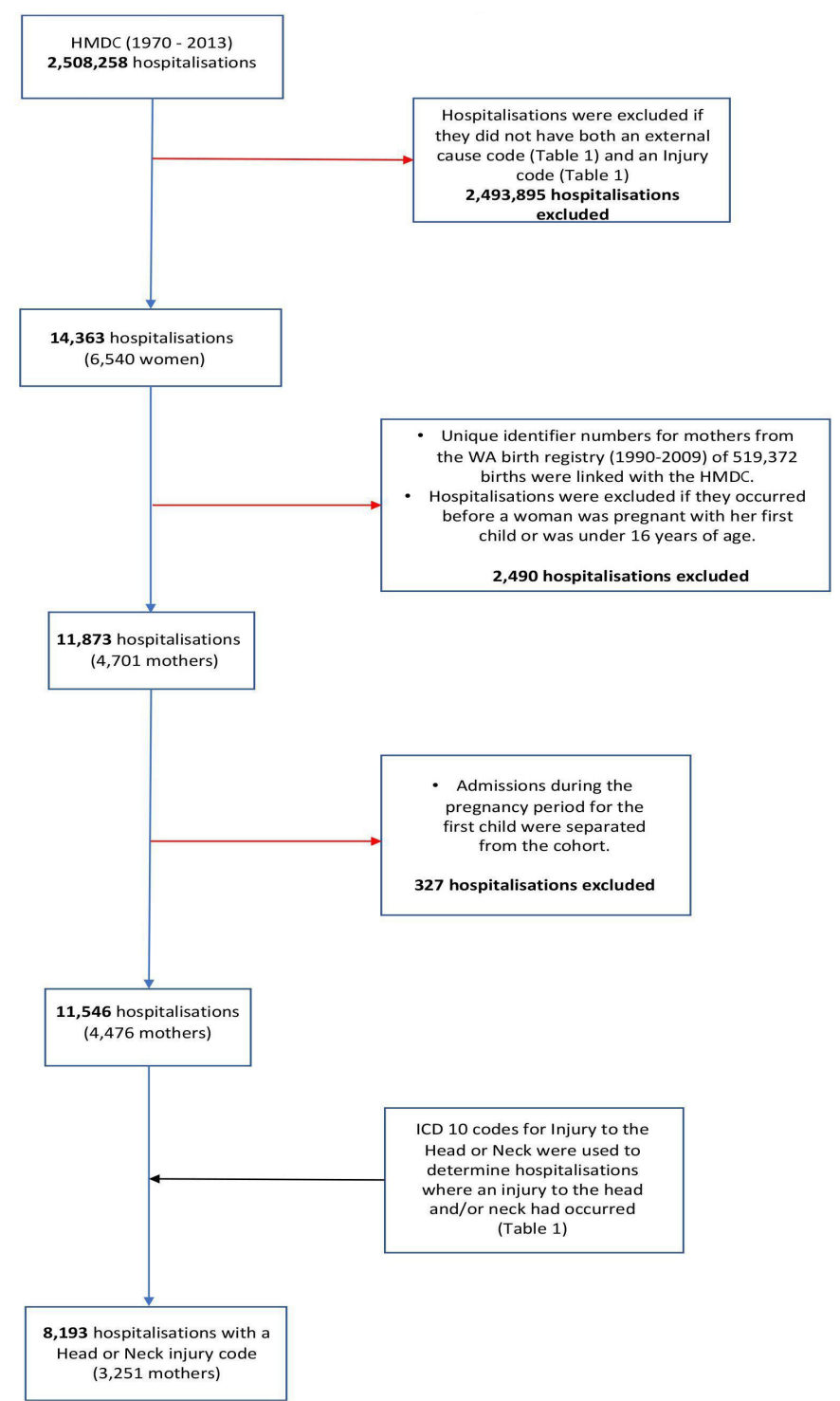

Figure 1 Hospitalisations selected for analysis. HMDC, Hospital Morbidity Data Collection; ICD-10, International Statistical Classification of Diseases and Related Health Problems, Tenth Revision; WA, Western Australia.

areas. Any records with missing data were excluded from the final analysis.

\section{Outcome variables of interest}

The primary outcome of interest (hospitalisation due to injury from FDV) for individuals was recorded as a binary response (yes/no).

\section{Primary independent variables}

The primary independent variables were sociodemographic characteristics including Aboriginality, age, SEIFA disadvantage, length of stay, number of children and age of first child.

\section{Statistical (analytical) approach}

Sociodemographic characteristics were summarised using descriptive statistics including percentages, mean and SD, with crude comparative analyses between groups (eg, Aboriginality by head injury) initially performed using $\chi^{2}$ tests for proportions and independent samples t-tests for continuous data. A generalised linear model for both univariate and multivariate logistic regression was used to identify any factors associated with risk of FDV, as well as social or demographic factors that may increase or decrease risk of injury. We report OR and 95\% CI. Generalised estimating equations, a flexible tool to model correlated data such as multiple admissions for individuals over time, were used to control for potential confounding variables including age, Aboriginality, disadvantage, length of stay, number of children and age of first child. All statistical analyses were performed using Stata V.15.

\section{Patient and public involvement}

Patients and/or the public were not involved in the design, or conduct, or reporting, or dissemination plans of this research.

\section{RESULTS}

A total of 4476 mothers had a total of 11546 hospital admissions due to assault-related violence over the period of the study. The mean number of admissions per mother was 3.1 (SD 3.5), with a range of 1-35 admissions. The mean age at first admission was 29 years old (range 16-92 years old, SD 7.9), with $62.4 \%$ of mothers under 30 years of age at the time of their first admission to hospital due to FDV. Of the cohort, $58.4 \%$ had between one and four admissions and the remainder had five or more admissions due to FDV.

Of all mothers admitted to hospital for FDV, there was an over-representation of Indigenous mothers (2620 $(58.5 \%)$ vs $1806(41.5 \%)$; table 2$)$. On average, Indigenous mothers had 4.0 admissions (SD 4.0) over the period of the study compared with non-Indigenous mothers who had an average of 1.5 admissions (SD 1.2) over the same period. There were also a greater number of mothers from areas with the highest level of social disadvantage (35.1\%; table 2).

Of the 11546 admissions to hospital for assault-related violence, there were $8193(71.0 \%)$ admissions for which an injury code to the head and/or neck was recorded (figure 1) for 3251 mothers. Aboriginal mothers contributed 6369 of the 8193 admissions (77.7\%), although being Aboriginal did not increase the odds that a mother would suffer a head injury due to FDV (OR=1.1, $\mathrm{p}=0.13$, 95\% CI 0.97 to 1.3 ). The most common injuries reported in the hospital admission data involving the head and neck were open wounds to the head (3753 admissions $(32.5 \%)$ for 1219 mothers $(27.2 \%)$ ), followed by superficial cuts and injuries to the head (3343 admissions (29.8\%) for 1484 mothers $(33.2 \%)$ ) and fractures of the head (1150 admissions $(10 \%)$ for 454 mothers $(10.1 \%)$ ).

A total of $327(2.8 \%)$ admissions occurred during the pregnancy period and 11546 admissions occurred after the birth of each mother's first child. Due to the small 


\begin{tabular}{|c|c|c|}
\hline $\begin{array}{l}\text { Women hospitalised as a result of injury } \\
\text { due to FDV }(\mathrm{N}=4476)\end{array}$ & n & $\%$ \\
\hline \multicolumn{3}{|l|}{ Indigenous status } \\
\hline Aboriginal & 2620 & 58.5 \\
\hline Non-Aboriginal & 1856 & 41.5 \\
\hline \multicolumn{3}{|l|}{ Index of social disadvantage $(n=3639)$} \\
\hline 1 & 1277 & 35.1 \\
\hline 2 & 303 & 8.3 \\
\hline 3 & 384 & 10.6 \\
\hline 4 & 1168 & 32.1 \\
\hline 5 & 507 & 13.9 \\
\hline \multicolumn{3}{|l|}{ Age $(n=4476)$} \\
\hline $16-20$ & 586 & 13.1 \\
\hline $21-25$ & 1140 & 25.5 \\
\hline $26-30$ & 1069 & 23.9 \\
\hline $31-35$ & 760 & 16.9 \\
\hline $36+$ & 921 & 20.6 \\
\hline \multicolumn{3}{|l|}{ Length of stay $(n=4476)$} \\
\hline $1<72$ hours & 3895 & 87.0 \\
\hline $2>72$ hours and $<10$ days & 533 & 11.9 \\
\hline $3>10$ days & 48 & 1.1 \\
\hline \multicolumn{3}{|l|}{ Number of children $(n=4476)$} \\
\hline 1 & 1254 & 28.0 \\
\hline $2-3$ & 2037 & 45.5 \\
\hline 4 or more & 1185 & 26.5 \\
\hline
\end{tabular}

FDV, family and domestic violence.

proportion of admissions during the pregnancy period, we were unable to undertake a comparative analysis of the intrapregnancy and postpregnancy periods, as such only frequencies for each injury type are reported for the intrapregnancy period in table 3. Most locations of the injury were similar for mothers during the pregnancy period, with the exception of injuries to the trunk $\left(\mathrm{S} 30-\mathrm{S} 39^{15}\right)$.

The most common location of injury coded in the hospital admissions data was the face and/or scalp including the orbit, and these areas were most commonly associated with superficial and soft tissue injuries such as bruising, lacerations, cuts, abrasions and open wounds (7079 admissions). The analysis showed that the upper and middle thirds of the face and scalp were the areas most likely to receive superficial injuries. ${ }^{16}$ The area most likely to be fractured was the mandible, which was fractured in 479 admissions and was almost equal to the sum of the next three most common facial fractures (nasal, maxillary and orbital floor) in hospital admissions for FDV (502 admissions combined). ${ }^{16}$ The mandible was also likely to be fractured more than once in the cohort of women experiencing the injury, with the 479 admissions being for 144 mothers. The number of admissions for which an injury to other areas of the body is coded is listed in table 3 .

After controlling for confounding variables, it was found that mothers with more than one child were $17 \%$ more likely to have an assault-related head injury hospitalisation than those with only one child $(\mathrm{OR}=1.17$, $\mathrm{p}=0.01,95 \%$ CI 1.03 to 1.30 ). The first year after the birth of a mother's first child was associated with a $40 \%$ greater likelihood of hospitalisation due to assault-related head injury when compared with mothers whose first child was between 7 and 16 years of age $(\mathrm{OR}=1.40, \mathrm{p}=0.03,95 \%$ CI 1.04 to 1.90 ). Mothers whose first child was between 1 and 6 years of age at the time of assault were $15 \%$ more likely to have a hospitalisation for assault-related head injury when compared with mothers whose first child was between 7 and 16 years of age $(\mathrm{OR}=1.15, \mathrm{p}=0.03,95 \% \mathrm{CI}$ 1.01 to 1.30 ). Table 4 shows the OR and $95 \%$ CI for the association between head injury and all sociodemographic characteristics examined.

The most common mode by which injury was inflicted for the entire cohort was 'assault by bodily force' $\left({\mathrm{Y} 04^{15}}^{15}\right)$, with a total of 6445 admissions (55.8\%) for 2839 mothers $(63.4 \%)$. This was followed by 'assault by blunt object' (Y00 ${ }^{15}$; 2210 admissions for 588 mothers) and 'assault by stabbing' and 'assault by unspecified means' (Y09 and $X 99^{15}$; 1717 admissions for 555 mothers). Of the mothers who sustained a head and/or neck injury, over half $(58.7 \%)$ had an admission where a physical assault code was recorded (4812 admissions for 2150 women), with the next most common being assault with a blunt object (1495 admissions).

Mothers with a head injury were 2.5 times more likely to stay in hospital for less than 72 hours compared with those staying for 10 days or more $(\mathrm{OR}=2.51, \mathrm{p}<0.001$, $95 \%$ CI 1.81 to 3.49$)$. When length of stay was examined for mothers hospitalised with and without a head injury, $88.5 \%$ of mothers with a head injury were found to have had a hospitalisation less than 72 hours in length as compared with mothers without a head injury $(72.6 \%)$.

\section{DISCUSSION}

To our knowledge this is the first study to analyse injury to the head and neck in victims of FDV admitted to hospital using linked longitudinal population-level data. Our findings show that there are important differences between mothers with only one child and those with more than one child, as well as mothers with young children (under 7 years of age) compared with those with older children (7-16 years of age). The most common injuries inflicted were to the face and scalp region in the form of cuts, abrasions, open wounds and bruising. The most common fracture was to the mandible, followed by nasal bone and orbital fractures. Physical assault was the most common mode of inflicting injury in the cohort, followed by assault with a blunt object. We were not able to compare the 
Table 3 Injury type and admission information for mothers

\begin{tabular}{llccc}
\hline ICD-10 code & Injury location & $\begin{array}{l}\text { Admissions, } \\
\mathbf{n}(\%)\end{array}$ & $\begin{array}{l}\text { Mothers, } \\
\mathbf{n}(\%)\end{array}$ & $\begin{array}{l}\text { Admissions during } \\
\text { pregnancy, } \mathbf{n}(\%)\end{array}$ \\
\hline S00-S09 & Head & $7950(69)$ & $3131(70)$ & $217(66)$ \\
S10-S19 & Neck & $599(5)$ & $299(7)$ & $14(4)$ \\
S20-S29 & Thorax & $1408(12)$ & $500(11)$ & $24(7)$ \\
S30-S39 & Abdomen, low back, lumbar spine and pelvis & $1130(10)$ & $470(11)$ & $64(20)$ \\
S40-S49 & Shoulder and upper arm & $1068(9)$ & $435(10)$ & $20(6)$ \\
S50-S69 & Elbow, forearm, wrist and hand & $2411(21)$ & $944(21)$ & $47(14)$ \\
S70-S79 & Hip and thigh & $711(6)$ & $299(7)$ & $27(8)$ \\
S80-S89 & Knee and lower leg & $1381(12)$ & $844(19)$ & $18(6)$ \\
S90-S99 & Ankle and foot & $358(3)$ & $118(3)$ & $5(2)$ \\
\hline T00-T07 & Multiple injuries & $47(0)$ & $27(1)$ & $2(1)$ \\
T08, T09 & Unspecified spinal & $80(1)$ & $40(1)$ & $0(0)$ \\
\hline T10, T11 & Unspecified upper limb & $91(1)$ & $45(1)$ & $4(2)$ \\
\hline T12, T13 & Unspecified lower limb & $57(1)$ & $29(1)$ & $2(1)$ \\
\hline T20-T32 & Unspecified burns, multiple injuries & $90(1)$ & $28(1)$ & $0(0)$ \\
\hline
\end{tabular}

ICD-10, International Statistical Classification of Diseases and Related Health Problems, Tenth Revision.

intrapartum and postpartum periods due to the comparatively limited numbers of admissions during the pregnancy period. However, mothers in the pregnancy period appeared to have a higher proportion of injuries to the trunk, which is consistent with other published literature. ${ }^{5}$

Previous literature published in the area examining the rates of injury to the head and neck as well as the location, type and mode of injury has generally involved small samples sizes or cross-sectional data only. ${ }^{341718}$ Our study confirms that the proportion of injury to the head and/ or neck area associated with hospital admissions for FDV is approximately $71 \%$, which is consistent with published literature in the area, which quotes rates of injury to the head and/or neck area of between $50 \%$ and $80 \%{ }^{19}$ in victims of FDV. We believe that the rate we have calculated is on the higher end of the published literature spectrum because injuries from FDV requiring hospital admission are likely to represent the more severe end of the FDV spectrum in turn.

Previous literature also suggests that the most common area of injury to the head and/or neck is the mid-third of the face,${ }^{190}$ with injuries in this region confined to the soft tissues. Our study confirms that the most common types of injury are soft tissue injuries such as bruising, open wounds and lacerations; however, both the upper and middle thirds of the face and the scalp were equally likely to be injured among mothers in our cohort.

We found that the most common mode of inflicted injury in FDV-related hospital admissions was physical assault, followed by assault with a blunt object, which is consistent with existing literature. ${ }^{19}$ Given that our cohort of mothers were admitted to hospital as a result of their injuries, it is interesting to note that even when mothers have more severe injuries requiring hospitalisation due to FDV, the mode of injury remains largely unchanged.

Our data demonstrate an over-representation of Aboriginal compared with non-Aboriginal mothers for assault-related admissions $(77.7 \%)$ and for injury to the head and neck, despite only comprising $3.3 \%$ of the population nationally. It has been well established previously $^{2}{ }^{10-12}$ that Aboriginal Australians have a significantly higher rate of admission for FDV. This study is the first to examine the types of injuries at the population level. Our analysis demonstrated that Aboriginal mothers had more than three times as many hospital admissions as a result of FDV-related injury than non-Aboriginal mothers, which is consistent with published literature in the area, ${ }^{21}$ although being Aboriginal was not, in itself, associated with a greater risk of assault-related head injury hospitalisation.

The finding that mothers with a head injury are more than twice as likely to stay in hospital for shorter periods (less than 72 hours) is a critical issue for front-line clinicians as there is limited time to engage appropriate services for a victim of FDV admitted to hospital. The need for multidisciplinary team intervention is essential to address the safety, health and well-being issues of mothers. Importantly discussing the needs of the mothers in relation to assisting with the safety of their children should also be considered during hospitalisations, with previous research finding that two-thirds of mothers had children in their care when they experienced violence. ${ }^{22}$

There are several limitations to this study that need to be considered. First, our findings are limited to describing the more severe cases of FDV, where the victim's injuries required them to be hospitalised, and thus cannot 


\begin{tabular}{|c|c|c|c|}
\hline Head injury & OR & $P$ value & $95 \% \mathrm{Cl}$ \\
\hline \multicolumn{4}{|l|}{ Age group } \\
\hline 20 and under & 1.12 & 0.37 & 0.88 to 1.43 \\
\hline $21-25$ & 1.2 & 0.05 & 1.0 to 1.44 \\
\hline $26-30$ & 1.18 & 0.04 & 1.0 to 1.39 \\
\hline $31-35$ & 1.03 & 0.72 & 0.87 to 1.21 \\
\hline 36 and over & 1 (base) & & \\
\hline \multicolumn{4}{|l|}{ Indigenous status } \\
\hline Non-Aboriginal & 1 (base) & & \\
\hline Aboriginal & 1.11 & 0.154 & 0.96 to 1.27 \\
\hline \multicolumn{4}{|l|}{ SEIFA disadvantage } \\
\hline 1 (highest disadvantage) & 0.93 & 0.45 & 0.78 to 1.12 \\
\hline 2 & 1.07 & 0.58 & 0.84 to 1.37 \\
\hline 3 & 1.02 & 0.89 & 0.81 to 1.27 \\
\hline 4 & 1.03 & 0.79 & 0.85 to 1.24 \\
\hline 5 (lowest disadvantage) & 1 (base) & & \\
\hline \multicolumn{4}{|c|}{ First child's age when head injury hospitalisation occurred } \\
\hline Less than 1 year old & 1.42 & 0.02 & 1.05 to 1.92 \\
\hline $1-6$ years old & 1.16 & 0.02 & 1.02 to 1.32 \\
\hline $7-16$ years old & 1 (base) & & \\
\hline
\end{tabular}

Number of children when head injury hospitalisation occurred

\begin{tabular}{llll}
1 & 1 (base) & \\
$2-3$ & 1.15 & 0.04 & 1.0 to 1.32 \\
4 or more & 1.21 & 0.01 & 1.04 to 1.41 \\
\hline
\end{tabular}

SEIFA, SocioEconomic Index For Areas.

be generalised to all women experiencing FDV. Second, many episodes of FDV in Australia are not reported, ${ }^{11}$ particularly those involving Aboriginal Australians, or those in rural and remote areas where access to health services is poor. ${ }^{11}$ Third, as a retrospective analysis of routinely collected administrative data, other potential confounders such as maternal and paternal education levels, marital status and rurality were not available for our analysis and thus were unable to be included.

This study represents the first attempt to explore FDVrelated hospitalisation injury types in a population-level data set. Head injuries are by far the most common type of injury due to FDV. Given the lack of literature in this area, it is imperative that further research is undertaken to explore all injury types and patterns that front-line clinicians may see in a victim of FDV given the ongoing and increasing nature of this issue in our society. In Australia the cost of violence against women and their children, to the healthcare system, in 2015-2016 was estimated at $\$ 22$ billion. ${ }^{2}$ It is clear that clinicians will continue to see presentations to hospital and perhaps primary care settings by mothers experiencing FDV, and recognition of injury types may help to prevent further admissions or episodes of FDV by engaging the appropriate services to assist mothers to improve their safety and well-being.

\section{CONCLUSIONS}

Mothers with an assault-related hospitalisation for an FDV-related injury are at significant risk of an injury to the head and/or neck. Of particular risk are mothers with young children and those with more than one child, even after controlling for other factors. Given that these assault hospitalisations are most likely due to FDV, the impact that this has on the mothers, their children and the ongoing cost to society and the healthcare system, care needs to be taken by clinicians to assess the injuries of women presenting to them and to consider the possibility of FDV where warranted. We believe our results to be generalisable to other populations due to the robustness of the data linkage ${ }^{7823}$ the prevalence of FDV globally, ${ }^{1}$ and other literature from smaller studies cited in this paper which have supported our findings in regard to head injury characteristics. While efforts are underway to improve the health gap in Aboriginal Australians in comparison with non-Aboriginal Australians, it is clear that more efforts need to be made to reduce the burden of FDV among Aboriginal mothers. The United Nations has identified reducing violence against women as part of its 2030 sustainable development goals, ${ }^{24}$ and therefore this issue should be seen as a priority within health and community settings.

Acknowledgements The authors acknowledge the partnership of the Western Australian Government Departments of Health, Communities, Education and Justice, which provided data for this project. The authors also want to thank the Data Linkage Branch of the WA Department of Health for linking the data.

Contributors VMB was responsible for study design, data analysis, manuscript drafting and final write-up. MKB assisted with study design, data analysis and manuscript drafting. JC assisted with study design, manuscript editing and write-up review. DP assisted with study design, data analysis planning and manuscript editing. LS-S assisted with study design, manuscript drafting and write-up review. MO'D collected the data, and assisted with study design, manuscript drafting and final editing.

Funding VMB has been supported by a Research Training Program (RTP) Fees Offset Scholarship.

Competing interests None declared.

Patient consent for publication Not required.

Ethics approval Ethics approval for this study was obtained from the WA Department of Health Human Research Ethics Committee (\#2012/37), the WA Aboriginal Health Ethics Committee (waiver) and the University of Western Australia Human Research Ethics Committee (waiver).

Provenance and peer review Not commissioned; externally peer reviewed.

Data availability statement Data may be obtained from a third party and are not publicly available. Data are kept securely by the Data Linkage Branch of the Western Australian Department of Health and can be accessed and linked on request once security processes have been followed.

Open access This is an open access article distributed in accordance with the Creative Commons Attribution Non Commercial (CC BY-NC 4.0) license, which permits others to distribute, remix, adapt, build upon this work non-commercially, and license their derivative works on different terms, provided the original work is properly cited, appropriate credit is given, any changes made indicated, and the use is non-commercial. See: http://creativecommons.org/licenses/by-nc/4.0/. 


\section{ORCID iDs}

Vishal Mahesh Bulsara http://orcid.org/0000-0003-1045-9512

Max K Bulsara http://orcid.org/0000-0002-8033-6123

Linda Slack-Smith http://orcid.org/0000-0001-5859-7055

\section{REFERENCES}

1 World Health Organisation. Global and regional estimates of violence against women: prevalence and health effects of intimate partner violence and non-partner sexual violence. Switzerland, 2013. Available: http://apps.who.int/iris/bitstream/handle/10665/85239/ 9789241564625_eng.pdf;jsessionid=3CF8E7A53C120C850DF8AE7A 427EB7CF?sequence $=1$

2 Australian Government, Australian Institute of Health and Welfare. Family, domestic and sexual violence in Australia. Canberra: AlHW, 2018.

3 da Nóbrega LM, Bernardino Ítalo de Macedo, Barbosa KGN, et al. Pattern of oral-maxillofacial trauma from violence against women and its associated factors. Dent Traumatol 2017;33:181-8.

4 Yamamoto K, Matsusue Y, Horita S, et al. Maxillofacial fractures associated with interpersonal violence. J Craniofac Surg 2019;30:e312-5.

5 Australian Institute of Health and Welfare. Family domestic and sexual violence in Australia: continuing the national story. Canberra, 2019. https://www.aihw.gov.au/getmedia/b0037b2d-a651-4abf-9f7b00a85e3de528/aihw-fdv3-FDSV-in-Australia-2019.pdf.aspx?inline= true

6 Australian Institute of Health and Welfare. Family, domestic and sexual violence in Australia. Canberra: AlHW, 2018.

7 Clark A, Preen DB, Ng JQ, et al. Is Western Australia representative of other Australian states and territories in terms of key sociodemographic and health economic indicators? Aust Health Rev 2010;34:210-5

8 Holman CD, Bass AJ, Rouse IL, et al. Population-based linkage of health records in Western Australia: development of a health services research linked database. Aust N Z J Public Health 1999;23:453-9.

9 Holman C, Bass AJ, Rosman DL, et al. A decade of data linkage in Western Australia: strategic design, applications and benefits of the WA data linkage system. Aust Health Rev 2008;32:766-77.

10 Meuleners LB, Hendrie D, Lee AH. Hospitalisations due to interpersonal violence: a population-based study in Western Australia. Med J Aust 2008;188:572-5.

11 Meuleners LB, Lee AH, Janssen PA, et al. Maternal and foetal outcomes among pregnant women hospitalised due to interpersonal violence: a population based study in Western Australia, 2002-2008. BMC Pregnancy Childbirth 2011;11:70.

12 Orr C, Preen D, Fisher C, et al. Trends in hospital admissions for intimate partner violence in Australian mothers with children born from 1990 to 2009. J Interpers Violence 2019;27

13 Youth Legal Service. What age can I consent to my own medical treatment? Perth, Western Australia, 2019. http:// youthlegalserviceinc.com.au/fact-sheets/what-age-can-i-consent-tomy-own-medical-treatment/

14 Australian Bureau of Statistics. What is SEIFA? - frequently asked questions (Chapter 2). Canberra, Australia: Australian Bureau of Statistics, 2006. https://www.abs.gov.au/AUSSTATS/abs@. nsf/Lookup/2039.0Main\%20Features42006?opendocument\#: : targetText=Index\%20of\%20Relative\%20Socio\%2Deconomic\% 20Disadvantage \%20(IRSD)\&targetText=This\%20means\%20that \% 2C\%20unlike\%20the,as\%20shown\%20in\%20figure\%202.1

15 World Health Organisation. International statistical classification of diseases and related health problems 10th revision (ICD-10), 2016. Available: https://icd.who.int/browse10/2016/en

16 Bulsara VM. Investigating injuries and hospital admissions in children and mothers who have experienced family and domestic violence: a retrospective study using Western Australian population-level linked data. Perth, Western Australia: The University of Western Australia, 2021.

17 Karakurt G, Patel V, Whiting K, et al. Mining electronic health records data: domestic violence and adverse health effects. J Fam Violence 2017;32:79-87.

18 Zieman G, Bridwell A, Cárdenas JF. Traumatic brain injury in domestic violence victims: a retrospective study at the Barrow neurological Institute. J Neurotrauma 2017;34:876-80.

19 Sheridan DJ, Nash KR. Acute injury patterns of intimate partner violence victims. Trauma Violence Abuse 2007;8:281-9.

20 Le BT, Dierks EJ, Ueeck BA, et al. Maxillofacial injuries associated with domestic violence. J Oral Maxillofac Surg 2001:59:1277-83.

21 Australian Government, Australian Institute of Health and Welfare. Hospitalised assault injuries among women and girls fact sheet. 184. Canberra: AlHW, 2017.

22 The Australian Bureau of Statistics. 4906.0 - Personal safety, Australia, 2016. Canberra, 2017. https://www.abs.gov.au/ausstats/ abs@.nsf/mf/4906.0

23 Trutwein B, Holman C, Rosman DL. Health data linkage conserves privacy in a research-rich environment. Ann Epidemiol 2006;16:279-80.

24 The United Nations. Sustainable development goals. The United Nations, 2019. https://www.un.org/sustainabledevelopment/genderequality/ 